\title{
Factor Analysis on the Endowment Insurance System Reform for Urban Workers in China: Based on the Perspective of Institutional Change Theory
}

\author{
Ning Jiang \\ School of Business Administration, South China University of Technology, Guangzhou, China \\ Email: janiechiang@qq.com
}

Received 10 March 2016; accepted 11 April 2016; published 14 April 2016

Copyright @ 2016 by author and Scientific Research Publishing Inc.

This work is licensed under the Creative Commons Attribution International License (CC BY). http://creativecommons.org/licenses/by/4.0/

(c) (i) Open Access

\begin{abstract}
The basic endowment insurance system for urban workers is the pillar arrangement of the whole endowment insurance system in China, which makes a fundamental influence on the construction of social security system. After the $18^{\text {th }}$ National Congress of the CPC, China ushered in the era of social pension system reconstruction. This paper reviewed the changing histories of endowment insurance system for urban workers, summarized the general characteristics of endowment insurance system for urban workers, and explored the factors of the endowment insurance system reform under a perspective of institutional change theory. It was found that the economic system reform, state-owned enterprise reform, and tax reform are the economic factors affecting the pension system transition, while the compartmentalization of administrative pattern and the conflicts of interest between government departments at all levels are the administrative factors to promote the reform of the endowment insurance system. There is new resistance of the comprehensive deepening reform within the new practice of institutional change, such as the dual-track system, endowment insurance model selection problem, and the overall planning for the whole country. The endowment insurance system in China is experiencing a critical period from the long-term reform to the mature stage.
\end{abstract}

\section{Keywords}

Endowment Insurance System, Institutional Change, System Reform, Social Security System

\section{Introduction}

The social endowment insurance system (EIS) is an important part of the social security system in China, and

How to cite this paper: Jiang, N. (2016) Factor Analysis on the Endowment Insurance System Reform for Urban Workers in China: Based on the Perspective of Institutional Change Theory. Open Journal of Social Sciences, 4, 23-30. 
has presented a distribution situation as fragmentation due to the historical and economic environment change. According to different beneficiaries it was divided into three categories: urban workers, urban residents and rural residents, while the urban workers were subdivided into enterprise workers, public institution workers and civil servants. Enterprises implement the basic endowment insurance system (BEIS); institutions still follow the traditional pension system. There are great differences between these two modes in terms of financing channels, plans, and pension benefits. Thus, it is called a dual track system with Chinese characteristics. As a result of the continued expansion of population as well as the size of system fund, BEIS for urban workers has become the pillar of the whole EIS in China. Its basic function is not only to improve the welfare of workers and remove their worries, but also to promote social equity and enhance national identity. The long-term accumulation characteristics and a huge amount of payment make a fundamental influence on the success of the whole social security system [1]. In 2012, the $18^{\text {th }}$ National Congress of the CPC re-emphasized the importance of reforming and improving the social insurance system of both enterprises and institutions, and put forward a core task to deal with the challenge of aging. Therefore, it is a difficult topic to comprehensively deepen the reform of BEIS for urban enterprise employees in current China. The study is mainly committed to solve this problem.

\section{General Characteristics of the Endowment Insurance System for Urban Workers in China}

According to the theory of institutional change, the change of EIS for urban workers in China is caused by both the institutional demand side and the supply side accordingly. As system's supply side, the government promotes economic development and society construction with corresponding EIS, and maintains stable operation of the system through sophisticated mechanism. Enterprises and employees are the demand side of the system. They defer to the mandatory norms of the system, but put forward more specific requirements to protect their own interests at the same time. For more ideal cost and revenue proportion, both of the sides game each other during the course of the reform of EIS, which breaks the institution balance and boosts institution change.

Since the foundation of PRC, EIS for urban workers have gone through three stages: the preliminary set up under planned economic system, the partly adjustment after market-oriented reform for state owned enterprises, and fundamental change from pay-as-you-go (PATG) to partly-cumulative system. With the deepening of economic system reform, EIS has entered a perfect stage of transition. Some characteristics emerged by EIS are as followed:

\subsection{A Mandatory Dominant Change Mean}

Reviewing the history of institutional change, it could be found that the state has absolute power throughout promoting the development of EIS. In 1951 the first complete social insurance law and regulation was promulgated, which was the first time in China; then in 1991, a decision on the reform of EIS for enterprise employees was published by the State Council, when the pension system was switched from national welfare system to personal responsibility system. Early in 1997, the basic mode of endowment insurance combined with both social pooling and individual account was formally determined. Aiming at the problem of the nominal account, the State Council proposed to fund the personal accounts in 2005, as well as to improve the basic mode. So far the whole process of institutional change is under the direct leadership of central government and the national legislature by issuing an administrative order or using legal means. This is obviously a state-oriented mandatory change mean.

Mandatory institutional change presents advantages of high credibility, great impetus, weak delay, and a low cost of monopolistic innovation cost. The higher efficiency of the implementation, the more complete replacement of the old system. However, once comprehensive promotion, the high risk of reform and lacking trial-anderror mechanism make the system difficult to withdraw or modify. Moreover, significant external effects may easily lead to free rider or other rent-seeking corruption phenomena.

Despite of a framework of mandatory institutional change, EIS also presents some characteristics of induced institutional change in the actual process of reform. For example, government once grants some independent rights to the pilot area, through the observation of experimental results, then learns from experience of changes to increase the feasibility of system. In 2000, the State Council put forward a proposal of using financial subsidies to supplement the social insurance fund. This sparked a comment about two solid approaches: fill the gap or 
fill the account, which lead to hesitation among eight provinces’ reform programs [2]. In the process of system transformation, the maximum selection of participants bring the institutional change a composition of demand induce to a certain extent, but the perspective of local income within induced changes may easily restrict the depth and breadth of system change and increase the resistance force of reform. In that case, induced institutional change is not suitable as the current dominant system change method for China.

\subsection{A Gradual Changing Process of Learning-by-Doing}

For quite a long time, there exists a debate of gradual or abrupt change about the extent of institutional change in the academic circles. The gradual theory emphasized that the institutional change is slow, step by step. Douglas C North [3], the leader of institutional change theory, thought that the process of change was gradual because of increasing returns within the institutional framework. Charles Lindbrom [4] also believed that the process of decision-making was a gradual process. Decision makers revised the current policy based on past experience, and the big policy change was composed of many small changes through a qualitative change caused by the accumulation. However, the abrupt change emphasized that institutional change was sharp and sudden, and the result was a complete departure from the state before the change. Transition of Russia and Eastern Europe in 1990s is a typical example of abrupt change, while this kind of revolutionary change often depends on violent means of the ruling class. Some scholars believe that for China's reform, the order of reform is more important than the speed. Proved by facts, China is more in favor of the gradual process of institutional change [5].

China's endowment insurance system change is a process of constantly trying and exploring. An initial national welfare pension insurance system under the planned economy, and a target of adaptation to the socialist market economy and the trend of population aging, are the unique national conditions of China while there is no experience from other countries or the past [6]. Limitation of people's knowledge of the new system, as well as the friction cost of internal and external systems, both call for a buffer period of the system. During the process of learning-by-doing, institutional supply side can gradually establish various institutional arrangements aiming at the problems in the process, so as to enhance the adaptability of the system to reality, and gain greater profit of institutional change.

\subsection{A Path Dependent Mechanism of Efficiency Priority}

Proposed by Huang S. A. [7], China's pension system reform was a kind of institutional change oriented by efficiency. In the long run, the marginal benefit of EIS has presented a development track of inverted U type. The total system gain was greater than the total cost, and marginal revenue increased first then decreased until the marginal revenue became zero. In order to continue obtaining the continuous marginal revenue, it was necessary to innovate through the system and restart the institutional change path to increase marginal benefit. Feng J. [8] emphasized the choice of EIS was connected with the alternation and coordination between fairness and efficiency. There are different interest groups in China's pension insurance system, whose choice preference of different modes of endowment insurance will play a different role in promoting the implementation of the system. In addition, Research group of China Economic Research Center of Peking University [9] proposed that, the incentive mechanism under the mode of accumulation could improve the staffs' enthusiasm more than the PAYG system, it was of advantage to resolve the redundancy dilemma of state owned enterprises. While the accumulation mode with higher average consumption rate, average consumption level, and lower tax rate distortion than the PAYG system, should be positive to the economic growth.

Although the mode of EIS is still a big controversy over domestic and abroad, a combination mode of social pooling and individual account rather than a fully fund accumulation system was chosen finally in China. This is closely related to the path dependence of the system and the national finance. From efficiency first and giving consideration to fairness ${ }^{1}$ to paying more attention to social equity ${ }^{2}$, the path of institutional change in China is a gradual reform through the bottom-up that greatly reduces the transition costs and improves the labor productivity of the whole people [10].

${ }^{1}$ Efficiency first and giving consideration to fairness was a political slogan proposed by President Deng Xiaoping in 1993, also the guideline of China's economic construction for over 10 years.

${ }^{2}$ Paying more attention to social equity was a supplementary policy proposed on the Fifth Session of Sixteenth Central Committee of the CPC in 2005. 


\section{Factors of the Endowment Insurance System Reform for Urban Workers in China}

\subsection{Factors of Economic Environment}

\subsubsection{Reform of Economic System}

Zheng G.C. et al. believed that economic reform and economic development were the basic factors affecting EIS [11]. The gradual reform of the economic system determined that the reform of EIS could neither exceed the economic system nor obtain the system innovation of some kind of reform mean. Likewise the experience of EIS reform from passive match to self-supporting explained that, EIS reform was effected by the whole economic system reform. After the gradual reform, the relationship among China's three basic interest groups has changed, and the liability of enterprise employees' pension insurance has become a policy burden for enterprises [12]. The redundancy effect and weakness of market power forced the system to take the road of social co-ordination.

With the advance of the incremental reform of China, economic compositions outside the system grew rapidly and the efficiency of non-state economic has gradually improved. Accordingly, in 1993 the pension system reform has made it clear to expand the coverage of BEIS, so the non-state owned economy were included in the system. After 2000, the market economic system reform entered into the period of overall advance, some problems in reform like the hidden debt and incentive problems began to emerge. In 2005, the State Council issued a series of policies following the pilot phase to determine the direction of the reform of the pension system again.

\subsubsection{Reform of State Owned Enterprises}

In addition to the impact of the economic system, reform of state owned enterprises to induce the deepening change of EIS is also a key factor. It was declared in a policy in 1993 that the establishment of modern enterprise system was the direction of the reform of state-owned enterprises, and the supporting enterprise pension system was also put onto the reform arrangement. Although the policy required having a partial accumulation, in practice, the accumulation was often difficult to achieve. Low level of social pooling, the gap between enterprises in different regions and different proportion of employees, and the heavy financial burden of enterprises without the economic assistance from governments in the market economic, all these conditions constituted a reality that personal account was the objective requirement of the reform of state owned enterprises, and partial accumulation system was the system choice of enterprise's self-promotion [13].

Since the reform of the pension insurance, redundancy of retired employees of state owned enterprises was alleviated on the one hand, while the huge transition cost has caused great pressure to the enterprise development on the other hand. Misappropriation of funds in individual accounts for paying the account gap was directly linked to the empty account problem, and the hidden debt problems have gradually become the difficultly cure ills for EIS. Chinese State Council once issued a document about reducing the proportion of state-held shares to support the reform in 2003, but failed because of the immaturity of capital market in the end.

\subsubsection{Reform of Finance and Taxation System}

As an important part of deepening the reform of economic system, reform of fiscal and taxation system has inevitably become one of the factors of EIS. From the welfare pension system arranged by state finance at first, to the liability of the state owned enterprises after the implementation of fiscal responsibility system, financial system acted as a barometer of EIS, as well as a reservoir maintaining the operation. The greatest consequence of fiscal responsibility system leads to the expansion of local financial power and the decline of national revenue budget, thus promoting the reform of tax sharing system and the change of EIS to a partial accumulation system. In 2000, Chinese government put forward a public finance framework to meet the requirements of the socialist market economy, and the expenditure of social security has become an important embodiment of government's public service expenditure under the framework. For the deepening reform of the pension system, improving fiscal and tax system is committed to solve the problem of historical debt, and make the social security fund coupling public finance system, in addition, is more conducive to improve the match mechanism of financial resources and powers, so as to promote the equalization of basic public services.

\subsection{Factors of Administrative Interests}

According to the theory of interest conflict, any economic system reform must depend on the objective econom- 
ic and social conditions, as well as the conflict or internalization process between the interests of the group based on the conditions [14]. Whether the interests divergence between national and local governments, or the one among different government departments, both have a profound impact on the reform of the pension system.

Thinking vertically, no doubt the contradiction of decentralization between national and local governments exists. Pressure of financial subsidies was transferred to the local government once in the name of social co-ordination from the national government. For instance, in the promotion process of funding the individual accounts, national government subsidized parts of the accounts that were funded only. However, personal accounts grew with individual pay wages over time, and it has turned out to be local finance responsible for incremental part of the subsidy, which has increased the burden of local finance.

While thinking horizontally, reform of EIS involves a co-promotion of a number of departments. There are differences of interest among different departments, which will lead to the differences in the course of the system reform. For example, in the first pilot of Northeast China, Liaoning mode and Hei-Ji mode represented two different financial subsidy and fund management model, reflecting the preference of the current and future financial pressure. Concerning the sustainability of fiscal revenues and the future payments, Chinese government was still inclined to choose Hei-Ji mode to supplement the funds.

The administrative division of a vertical and horizontal crossing has not only brought significant benefit divergence, but also restricted the system reforming from the fragmentation co-ordination to a provincial overall planning. Zheng G.C. believed that regional division is the fundamental flaw of BEIS [15]. The improvement of the overall level will lead to the re-distribution of the management right of the endowment insurance premium, which will trigger greater transition friction. Under the current mode of fragmentation co-ordination, integration of departments and regions at different levels makes the provincial social security department execute only the work instruction relationship with lower social security department, which might hinder the implementation of the provincial co-ordination. Zheng B.W. agreed that only narrowing the co-ordination part and expanding the account size can prevent the moral hazard in developed areas, thereby to improve the overall level of social planning [16].

\section{Resistance Analysis of the Endowment Insurance System Reform}

\subsection{Transformation Problems about Double-Track System towards Integration System}

Once established in the special period of social transformation in China, double-track system was the guideline and policy-making with the purpose of efficiency and equity principles, the performance of which in EIS was the different charge and revenue models between urban enterprise employees and government-institution employees. Currently, according to the "Decision on Improving the Basic Endowment Insurance System for Enterprise Employees”, issued by the state council in December 2005, enterprise workers implement that the enterprise payment accounts for 20 percent of the total amount of wages, and the unification scale of individual accounts is adjusted to 8 percent basis, all formed by the individual payment, furthermore the unit payment is no longer assigned to individual accounts. After retirement, the monthly standard of basic endowment pension is based on the local average wage of on-post workers and own payment monthly last year, and it will be paid 1 percent for each a full year. But the pension of civil servants and institution officers is deterministic, judged by the wage standard of retired personnel and with reference to a certain proportion of the last month's wage before retirement, meaning the longer working life, the higher proportion.

With the rapid development of economy and the improvement of the price level, the interest value, policy and financial dilemma of double-track system occur correspondingly. The pension income disparity between the staff of project units is becoming more and more significant. Contrary to the 90 percent of the retirement salary for government and institution, the endowment pension for enterprises could only be up to 60 percent. What's more, the endowment pension for enterprises is compulsory. The paid endowment pension adjusts on a wide range with the factors of price fluctuation and economic growth, and flexibility of individual domination is high. But the adjustment of endowment pension for government and institution is based on state or local financial regulation, synchronizing with the staff salaries. Chen R.R. [17] believes that the integration of EIS for government-enterprises institutions is a major adjustment of interest relationship, and the biggest challenge and key of reform is the coordination of interest relationship among groups. EIS for government and institution follows a Welfare-type EIS, enjoys higher pension than enterprise employees and payment basement of stable state financial, which is a big obstacle for the reform of integration system as a vested interest group. The pension gap in- 
duced by double-track system will continue to expand in accordance with current distribution model, making the pension expenditure be a heavy burden on the state financial.

On January 14, 2015, a proposal about the basic endowment pension system combined with social and individual accounts for government and institution employees was raised by the State Council. The integration reform has great effects on releasing the financial pressure, improving people's livelihood and promoting social equity. From the view of policy guidance, a basic principle of the reform is establishing enterprise annuity and the basic endowment insurance system synchronously. Corresponding with the enterprise annuity, the government and institution implement the compulsory occupational annuity, ensuring the promotion of integration system but not destroying the existing pattern. Although the concrete scheme of integration reform has not yet been announced, the trend of it will certainly trigger fundamental change of BEIS and the enterprise annuity.

\subsection{Selection Problems about Endowment Insurance System}

As one important area, EIS has always attracted the attention of academia and the public. Recently, many reform measures have been carried out to gradually improve EIS, like the endowment insurance integration plan for urban and rural residents. However, some scholars believed that these measures were implemented under the framework of existing system without fundamental change for EIS [18]. In 2013, the general arrangement of EIS was started by government, and many research institutions and scholars suggested the model reform, from current combined system to nominal account system, should be adopted. Under the dual economy condition, the possibility of moral hazard in developed areas will exist as long as the existing part of social pooling, declared by Zheng B.W. [16]. Complete nominal account has a significant positive effect on reducing the overall division, expanding the size of account and thus improving the level of social pooling. The individual account is actually a bookkeeping and non-access type book for the individual with payment for personal account. The funding personal accounts reform of EIS gives the individual a psychological guarantee which can solve the incentive problem. If contemporary people want to get a sustainable endowment pension and minimize the transition cost of commitment meanwhile, the nominal account system seems to have more practical significance, under the circumstance that the state financial could not afford to pay a one-time repayment of deficit account. Wang X.M. [19] also believed that many existing problems, like insufficient motivation, venture investment and huge transition cost can be easily solved in nominal account system.

However, some other people think that the core element of pension system is generational relation, income redistribution reflected by payment method and risk-bearing body of elderly income [18]. Pension model selection is influenced by economic and social environment, international factors, stakeholder needs and internal financial sustainability comprehensively. Actually, BEIS in China is a hybrid model. For example, the basic pension part is a PAYG benefit type, and the funded personal account part is a full-accumulated contribution type, while the unfunded personal account part is a PAYG contribution type. Even the Swedish model of nominal account system also retained 25 percent of the funded account, consistent with China's.

In addition, nominal account couldn't achieve lifelong payment if one wants to balance the finance, for fear that the individual account fund after use may fall into poverty trap of elderly and is contrary to the basic function and target of system. Moreover, from the perspective of social security system, if BEIS was transformed into nominal account totally, the income redistribution function will be completely lost and the individualism and egoism tendency will be reinforced, contrary to the basic spirit of socialist society. Dialectically, though the significant advantage, the nominal account is not yet fully alternative to the mixed mode of EIS in the current reform environment.

\subsection{Problems about National Overall Planning}

One of the important characteristics of fragmentation of EIS for urban workers in China is still in the region segmentation pooling. Currently, only Beijing, Shanghai, Tianjin, Chongqing, Shanxi, Qinghai, Xizang and other minority provinces, municipalities, autonomous regions achieve provincial unified revenue and expenditure of basic endowment pension, and majority of the provinces, autonomous regions still remain in stage of establishing provincial or municipal adjusting gold, and even the provincial adjusting gold is not prepared to be established for some individual provinces. Therefore, for the EIS overall planning condition still remaining in city level, regional fragmentation also began to expose more and more problems.

Firstly, the regional fragmentation descends the national-level systems to the regional differentiation ar- 
rangement, resulting in the increase of contribution rate gap between different regions, directly manufacturing the malformation pattern about the endowment pension fund of co-exist of surplus and loss conditions between different regions, and destroying the equity principle of EIS financing. Secondly, this pooling pattern weakens the national identity in a certain extent, restricts mutual assistance function of a social system, causes adverse effects of labor cost and labor flow under the market economy condition, and profoundly impairs the regional coordinated development. In addition, the non-unified contribution base and rate, the high nominal contribution rate, the unsolved problem of the deepened effect of capital economics on fund, the impaired credibility of system triggered a crisis of public confidence and anxiety, which directly hindered system optimization and reform process. Various negative effects show that it is necessary to transform the regional segmentation overall planning to national overall planning.

Using the long-term endowment insurance calculation model, Yang Jun calculated the financial situation between 2015 and 2050 [20]. It points out that after overall nationwide, the coverage of EIS will extend, the investment return rate of overall fund and actual contribution rate will improve, thereby enhancing the social security fund subsidies level, improving the growth mechanism of endowment pension gradually, postponing the statutory retirement age to the same level of productivity. The national overall planning of endowment insurance has been made clear by the major reports of the $18^{\text {th }}$ National Congress of the CPC and the $12^{\text {th }}$ Five Year Plan national planning for social security. Once the Research and Development of BEIS Plan was classified as the focus of reform by the Chinese national government in 2013, but the consequence was not good and greater resistance existed in fact. On March 5, 2015, Premier Li stated that promotion of overall planning of BEIS would be listed in the 2015 government jobs. Thus, as the established policy objective, the reform of national overall planning should be implemented urgently.

\section{Conclusions}

Experiencing several major historical changes, EIS for urban workers in China has formed a relatively complete framework for reform and entered an institutional change stage of virtual significance. The mandatory change mean supplemented by inducement, the gradual changing process dragged by practice and the path-dependent mechanism with priority of efficiency are the common characteristics of EIS. The government, enterprise, and employees make up three interest groups that influence the EIS structure. They win the balancing situation between system reforming and overall level of social development through constantly game and coordination mutually.

The influencing factors on EIS reform are complicated. Economic system reform and improvement of the level of economic development constitute a crucial environmental foundation for EIS reform. The state-owned enterprises' reform is the cause and premise. Hence, a management model of the combination of social pooling and individual account established around modern enterprise system is the coordinating consequence of Chinese social welfare security and independent income distribution beneath the market mechanism. As an important component of comprehensive deepening reform, fiscal and tax reform can further promote the reform. While the interest divergence induced by China's special compartmentalization administrative system has played an important role in the modes choice. For a long time, the fragmentation situation of EIS has exposed more and more negative issues, so it is urgent to speed up the overall planning at the provincial or national level, and build up a unified EIS in the end.

Now, EIS in China remains in a critical period from long-time experimental reform to mature and sustainable development [21]. This round of reform is imperative to absorb the past experience, fully respects the objective law, establishes new horizon of macro-control and micro-equilibrium, thus constituting unified EIS, which is wildly shrouded, highly trusted, and balances regional coordinated development and the labor free flow.

\section{References}

[1] Zheng, G.C. (2013) National Pooling: Cure for the Optimization of Endowment Insurance System. Guangming Daily.

[2] Kang, H.Z. (2006) Transformation Analysis of Endowment Insurance System for Urban Workers in China. Capital University of Economics and Business, Beijing, 17-21.

[3] Ren, B. (2006) Endowment Pension Reform Program of Eight Provinces Are at Loose Ends. Finance, 10, 92-93.

[4] Lindblom, C. (1994) Decision-Making Process. Shanghai Yiwen Press, Shanghai, 131-133.

[5] North, D.C. (1998) Institution, Institutional Change and Economic Performance. Shanghai Triple Bookstore, Shanghai, 
193-194.

[6] Zhang, X. (2004) The Abrupt Change and Gradual Change of Institutional Evolution—On the Order Is Important Than Speed. Research of Institutional Economics, 2, 182-197.

[7] Huang, S.A. (2000) Three Hypotheses about Institutional Change and Its Verification. Social Sciences in China, 4, $37-$ 49.

[8] Feng, J. (2004) The Alternation and Coordination of Fairness and Efficiency: The Redistribution Effect of China's Endowment Insurance System. World Economic Papers, 1, 24-36.

[9] Economic Research Group, China Economic Research Center, Peking University (2005) The Choice of Endowment Insurance System in China: Motivation and Growth. Journal of Financial Research, 5, 1-12.

[10] Deng, Z. (2014) Path Dependence, Policy Diffusion and National Autonomy. Academic Research, 10, 38-44.

[11] Zheng, G.C. (2002) Changes and Evaluation of Social Security System in China. Chinese Renmin University Press, Beijing, 67-78.

[12] Lin, Y.F., Cai, F. and Li, Z. (2000) Reform of State Owned Enterprises in China. United Publishing Company, Taipei, 113-127.

[13] Su, X.C. and Yang, Z.Y. (2007) Economic Analysis on the Change of Endowment Insurance System in China. Journal of Financial Research, 33, 15-27.

[14] Lei, G.Q. and Su, X.C. (2010) Analysis on the Change of Endowment Insurance System in China. Journal of Xiamen University (Philosophy and Social Sciences), No. 1, 55-61.

[15] Zheng, G.C. (2015) From the Regional Planning to the Whole Country-The Only Way to Deepen the Reform of the Basic Pension Insurance System for Employees in China. Journal of Renmin University of China, No. 3, 2-11.

[16] Zheng, B.W. (2007) China Should Not Follow the Social Security Tax from the International Development Trend. Macroeconomic Research, No. 3, 17-21.

[17] Chen, R.R. (2015) Problems and Strategy about Double-Track System towards Integration System. Journal of Career Academy Jiamusi, No. 6, 358-359.

[18] Lu, Q. (2015) Theory on Choosing Pension Model-Why the NDC Model Is Not Suitable for China. Journal of Renmin University of China, No. 3, 19-25.

[19] Wang, X.M. (2005) Global Public Endowment Pension System Reform and China's Choice-The Empty Account, Linked to GDP, Is More Reliable and Accessible than the Real Account, Linked to the Capital Market. World Economic Papers, No. 6, 52-71.

[20] Yang, J. (2015) An Analysis of the Influence Factors of the Financial Status of Employee Basic Old Age Insurance System-A Study on the Social Pooling System. Journal of Renmin University of China, No. 3, 12-18.

[21] Wu, L.X. (2012) Study on the Mechanism of Endowment Insurance System Changes in China. Capital University of Economics and Business, Beijing, 99-101. 